\title{
Editorial
}

\section{Navigating business-to-business marketing}

\author{
Journal of Direct, Data and Digital Marketing Practice (2015) 16, 241. doi:10.1057/dddmp.2015.26
}

Welcome to this special business-to-business (B2B) edition of the IDM Journal. The IDM manages a series of leadership and practice councils. These advisory boards provide a professional and experienced perspective of marketing in practice. Within the B2B Marketing Council we have a superb representation of marketing professionals from both agency and client side. The council members hail from globally recognized organizations, such as Google, MasterCard, IBM, Adobe and Deloitte. We also have executives from some of the leading UK B2B marketing agencies, such as OgilvyOne, Junction, MOI, Really B2B, Think Direct, CleverTouch and Foss Initiatives.

The B2B Marketing Council meets quarterly with senior members of the IDM with the overall purpose of advising the IDM staff and tutors on how to stay current for their members and provide direction on future marketing courses that will be required by marketing students around the world. The B2B Marketing Council wants to ensure that we provide challenging content that addresses some current marketing issues and also fuels the marketing debate to inspire more people to start a career in B2B marketing. We want to challenge them to improve their skills and inspire them to achieve more in their current roles, their businesses and their careers.

B2B marketing is a very exciting field, sometimes not as recognized as business-to-consumer marketing, but just as challenging and even more rewarding. The market for experienced B2B marketing candidates is on the increase and is set to grow year-on-year as more businesses expand. Let us hope that some readers will be able to include their thoughts and experiences in similar special issues of the IDM Journal in the not too distant future.

The roles of the B2B Marketing Council and this Journal are not dissimilar. The council aims to provide a current perspective on the state of $\mathrm{B} 2 \mathrm{~B}$ marketing, to create debate, to challenge thinking, and to provide learnings and solutions around what is currently being discussed in firms up and down the country. The articles included in this special issue of the Journal are written to provide observations based on experience on how to become a better B2B marketer for your business.

The IDM will focus on seven key marketing topics in 2015 and beyond. These are email marketing, search engine marketing (search engine optimization and pay-per-click), content marketing, social marketing, marketing automation, user experience (UX) and Google Analytics. Therefore, it made sense for the members of the B2B Marketing Council to concentrate on one or two of these topics to provide their thoughts, experiences and solutions.

The articles are all of a very high quality. As a reader, you are gaining access to some relevant and exclusive content. If we take the case study provided by IBM on Wimbledon 2014, for example, the overview, learnings and results are truly inspiring and achievable not just by a global brand. Marketing automation seems to be the marketing technology topic of the moment and I am not sure whether this is a good or a bad thing. I think the name is deceptive and extremely over-played, just like the term customer relationship management, or even social media. But the whitepaper by Andrew Buckley of Mastercard really helps us to understand the impact of marketing on the rest of the business. Like the other articles you will find in this issue, the perspectives and research you are about to read are truly outstanding.

Andy Grant 